\section{Bioética no cuidado e atenção do nascido interssexo: necessidade de revisão na prática clínica}

\section{Freitas, D.C.A.}

Programa de Desenvolvimento Territorial Sustentável na linha de pesquisa de Políticas Publicas - Universidade Federal do Paraná - Setor Litoral

\section{Guimarães, M.A.}

Departamento de Patologia e Medicina Legal da Faculdade de Medicina de Ribeirão Preto - Universidade de São Paulo. E-mailmag@fmrp.usp.br

\section{Carezzato, C.L.}

Centro de Medicina Legal (CEMEL) - Departamento de Patologia e Medicina Legal-FMRP-USP

\section{Mendo, C.T.M.}

Departamento de Patologia e Medicina Legal da Faculdade de Medicina de Ribeirão Preto - Universidade de São Paulo. ${ }^{2}$ Curso de Medicina da Universidade do Mato Grosso UNEMAT

\section{Garcia, S.B.}

Departamento de Patologia e Medicina Legal da Faculdade de Medicina de Ribeirão Preto - Universidade de São Paulo

PALAVRAS-CHAVE: Interssexo, Mutilação genital, Autodeterminação de gênero, Autonomia, Bioética

Introdução - A revista de Nature [1] relata que o percentual de pessoas intersexuais é de $1 \%$, proporção similar àquela de pessoas com os cabelos ruivos, um número muito significativo de pessoas. Esse termo é usado para uma variedade de condições nas quais uma pessoa nasce com uma anatomia reprodutiva ou sexual que não parece se encaixar nas definições típicas de mulher ou homem. Na década de 1950, uma equipe de especialistas médicos da Universidade Johns Hopkins [2] desenvolveu o que veio a ser chamado de sistema de "sexo ótimo para criação" para o tratamento de crianças com interssexo. A idéia consistia que em casos de intersexuais a designação de gênero fosse resolvida cedo, para que as crianças crescessem e se tornassem "bons" meninas e meninos (dentro do padrão heterocisnormativo). Sob a liderança teórica do psicólogo John Money, a equipe de Hopkins acreditava que o gênero seria tutelado pela criação e poderia transformar qualquer criança em uma menina ou menino "real" se fizesse com que seus corpos parecessem corretos (antes dos 18 meses de idade), fazendo com que eles e seus pais acreditassem na atribuição de gênero. Método - Revisão da literatura. Resultados - A equipe de Hopkins referia que desde cedo que as crianças deveriam saber a verdade sobre suas histórias intersexuais de maneira adequada à idade, mas na prática, muitos provedores de cuidados médicos mentiam para seus pacientes ou retinham ativamente informações sobre a história médica deles, o que configura uma violação bioética dos critérios de verdade, sendo que posteriormente a própria literatura médica frequentemente aconselhavam médicos sobre como mentir para pacientes com estados intessexuais, o que fez esse modelo se espalhar pelo mundo todo. Essa teoria levou à realização de milhares de mutilações que não respeitavam a identidade de gênero e a autonomia dos seus pacientes. Conclusões - Atualmente, grupos em todo mundo de ativistas da causa de interssexos, associados à sociedade civil e órgãos como a ONU vem manifestando seu desagrado a esta pratica que não respeita os corpos de pessoas interssexo e que não avalia de modo longitudinal as consequências dessas práticas que visam apenas padronizar corpos que nascem discordantes biologicamente, ao invés de aguardar pela sua maturação biopsíquica e ter a decisão do paciente, sujeito da intervenção, a autodeterminação de seu próprio gênero [3]. No Brasil temos uma resolução, a 1.664, de 2003 do Conselho Federal de Medicina que legitima tais práticas.

\section{REFERÊNCIAS}

[1] C. Ainsworth. Nature, 518, 288-291 (2015).

[2] Intersex Society of North America - ISNA.

http://www.isna.org/bibliographies

[3] M.A. Guimarães (2018). Pereira Filho, A., Marques Filho, J. - Bioética: Dilemas e Diálogos Contemporâneos. ISBN 978-85-89656-32-0. 